\title{
What is love? A complex systems perspective
}

\author{
Ana Teixeira de Melo
}

Centre for Social Studies, University of Coimbra, Portugal

\section{Leo Simon Dominic Caves}

York Cross-Disciplinary Centre for Systems Analysis and Dept. of Biology, University of York, United Kingdom

Ana Teixeira de Melo, Centre for Social Studies, University of Coimbra, Portugal;

Address: Apartado 2001, EC Praia da Granja, 4411-901 São Félix da Marinha, Portugal; Email: anamelopsi@gmail.com 


\section{What is love? A complex systems perspective}

Love is a fundamental dimension of being human and a powerful resource for flourishing and well-being. Yet, it is still insufficiently understood. Despite advances, the Science of Love remains a fragmented field, producing mostly partial, fragmented and unintegrated views on love. In this paper, we present a novel perspective on love based on a complex systems perspective, building from a theoretical framework of families and family relationships as complex systems. We establish a set of preliminary assumptions for the development of an Integrated Theory of the Complexity of Love (C.ofLove) and for a novel inter and transdisciplinary research approach, as the foundations for an Integrated Science of Love.

Keywords: interpersonal relations; family relations; wellness 


\section{On the science of love}

The impact of positive emotions on well-being, flourishing and resilience is well documented (Fredrickson, 2000). Close relationships, including family relationships, can be powerful sources of positive emotions. They are known to be "universally important" and fundamental ingredients for happiness (Diener \& Seligman, 2002; Diener \& McGravan, 2008; Saphire-Bernstein \& Taylor, 2013) as well as essential routes to well-being and resilience (Simpson \& Campbell, 2013). Love may be a fundamental dimension linking relatedness to well-being (Reis \& Aron, 2008; Reis, Collins \& Berscheid, 2000).

Although often conceived as an emotion, love deserves a different status from positive emotions. Love appears to be a form of "supreme" experience that surpasses the beneficial effects of common positive emotions (Fredrickson, 2013). Its inherently relational nature may underlie its capacity to empower, strengthen, motivate, heal, expand capacities and build happiness, above other human strengthens, while, at the same time, enhancing them (Fredrickson, 2013; [blinded for review], in preparation a; [blinded for review], in preparation b).

The past decades have brought significant advances in the sciences of relationships (Reis, Aron, Clark, \& Finkel, 2013). Psychology has responded to Harlow's call (1958) to explore the nature of love and new routes have been opened for scientific investigation (Berscheid, 2010; Hojjat \& Cramer, 2013; Sternberg \& Weiss, 2008).

However, despite meaningful advances, the efforts to investigate love are still insufficient and, above all, dispersed. The Science of Love appears as a fragmented field (Berscheid, 2010; Harvey \& Wenzel, 2006) producing only partial, scattered and unintegrated views on love. As love remains insufficiently understood, the bridges 
between theory and practice are still to be fully explored and the translational character of the science of love awaits development. Nevertheless, preliminary research suggests that love may be a powerful resource promoting human flourishing and well-being, positive human change and resilience that could be targeted by interventions (Fredrickson, 2013; [blinded for review], in preparation).

The variety of (in)definitions and the multiple uses of the expression 'love', both in lay and scientific discourses, has contributed to a conceptual muddle, within and between disciplines, that hinders scientific integration and advance (Berscheid, 2010). Different theories of love are associated with different definitions (Aron, Fisher \& Strong, 2006; Berscheid, 2010; Noller, 1996; Sternberg \& Weis, 2006; Reagan, 2008; Reis \& Aron, 2008). There is also a diversity of empirical studies where love-related themes are approached without a clear conceptual framework (Berscheid, 2010; Beauregard, Courtemanche, Paquette \& Landry St-Pierre, 2009; Zeki, 2007). The existing models are mostly descriptive, exploring possible "components" or correlates of love (Hojjat \& Cramer, 2013; Sternberg \&Weiss, 2008). Reductionist approaches prevail that, focused more on the content rather than on processes, attempt to pin love down to specific properties (e.g. compassion, empathy, positive communication) or aggregate dimensions (e.g. attachment) (Fehr, Sprecher \& Underwood, 2008; Hojjat \& Cramer, 2013; Shaver, \& Hazan, 1988; Sternberg \&Weiss, 2008). Moreover, lists of related concepts and prototypes have been constructed that reveal the 'fuzziness' of love (Fehr \& Russell, 1991). However, none of these descriptors alone is sufficient to understand the experience of love, how it emerges, unfolds and changes people's lives. Love is not reducible to any single property of the individuals or relationships, or their linear sum. It is emergent: other than the sum of its parts (Goldstein, 1999). The listing of concepts related to love does not truly address questions such as "what is love" (as 
opposed to 'what is involved in love?' or 'what leads to love?'), “where is love?", "when is love?", or "how does love operate?".

Although love is a relational property that cannot be localised or reduced to the level of the individuals (Fredrickson, 2013; [blinded for review], in preparation; Vaughan, Eisenberg, French, Puwono, Suryanti, \& Pidada, 2009), research is often focused on them (Regan, 2011; Underwood, 2009). In fact, the Science of Love has neglected the role of the dynamics of coordination between individuals, in shaping the experience of love (Passos, Davids \& Chow, 2016; Reis \& Aron, 2008).

To date, love has been investigated without a thorough consideration of the complex, multi-level organisation of human relationships and the role of different levels (e.g. individual vs dyad vs networks of relationships) ([blinded for review], in preparation; [blinded for review], 2014). The relation between these different levels is seldom explored, and additionally, there is little recognition that some properties associated with love may be emergent ([blinded for review], 2014).

There have been some recent attempts to build models of love that include different dimensions and levels of organisation (Underwood, 2009). In general, however, the Science of Love has not fully attended to the complex systemic relational organisation of love as involving a multiplicity of facets, dimensions and processes (e.g. levels of organisation and corresponding properties; conditions leading to emergence; change and development processes; triggers for activation; consequences or effects) that need to be both distinguished and related. On the other hand, although there is recognition of the temporal/dynamic nature of love (Berscheid, 2010), studies lack, in general, a focus on dynamics.

Research studies tend to focus on different "types of love" (predominantly "romantic love") (Berscheid, 2006; Regan, 2011). However, the focus on taxonomy, 
may have contributed to a delay in addressing the problem of the definition of love (Berscheid, 2010). Taxonomies are often proposed without a clear statement of what is the nature of "the thing" that is being classified into types (Harlow, 1958; Noller, 1996). There is evidence pointing to a sort of 'general' love, underlying even the different types of romantic love (Graham, 2010). Research has shown that some features (e.g. trust, friendship, caring, respect, intimacy and compassion) and types of relationships (e.g. companionate and familial) are better examples of a general notion of love (Fehr, 1994; Fehr, 2006; Fehr \& Russell, 1991; Fehr \& Sprecher, 2009).

The neurosciences and neurobiology of love have opened new realms for exploration (De Boer, Van Buel, \& Horst, 2012; Cacioppo, Bianchi-Demicheli, Hatfield, Rapson, 2012; Zeki, 2007). Nevertheless, studies are not always theory-driven and the results are not always discussed in relation to existing theories. The development of an integrated Science of Love requires an overarching theoretical framework where the outputs of research studies, conducted from different perspectives, can be synthesised and positioned in relation to each other. This approach is likely to benefit the exploration of novel routes to the production of meaningful translational impact.

Most commonly, love is defined as an emotion (Gonzaga, Keltner, Londhal \& Smith, 2001; Shaver \& Hazan, 1988), a type of affect or cognition (Fehr, Sprecher \& Underwood, 2009; Tomkins, 1984), a motivational state (Aron, Fisher \& Strong, 2006) or a type of bond (Shaver \& Mikulincer, 2006). Love has also been tackled at the discursive level as a type of relational narrative (Sternberg, 2006) and social construction (Dias, Machado, Gonçalves \& Manita, 2014). However, each of these perspectives leaves certain facets of love unexplored or unintegrated. The experience of love cannot be understood through any of them in isolation. 
Currently, the science of love presents only partial, fragmented, sometimes overlapping, but generally unintegrated views of love. It could well be compared to the Indian parable of the blind men and the elephant (Goldstein, 2010), where each model and theory (the blind men) appear to be looking only at fragments of what love (the elephant) might be, without being able to put the parts in context and see the whole picture. They proceed without a full awareness of how their perspective relates to those of the others, and lack the tools (both theoretical and methodological) to build dialogues and coordination in ways likely to foster the emergence of a synthesis and new understanding.

The current status of the Science of Love signals the complexity of the phenomenon. The perspective of complex systems has developed from the recognition that the natural or social worlds cannot be approached through traditional reductionist and mechanistic approaches (the pervasive legacy of the Newtonian worldview) without significantly limiting our understanding (Capra \& Luisi, 2014). Many of the paradigmatic limitations that hinder scientific advance in other disciplines are still dominant in mainstream Psychology (Toomela, 2004), and in the Science(s) of Love, leaving it in a relatively blind state in face of the complexity of love. Under the general scope of a Complexity Science, new theories and methods have been developed and integrated to approach the complexity of the world, in a more congruent way (Byrne \& Callaghan, 2013; Capra, 2007; Érdi, 2008, Urry, 2005). The complexity turn (Urry, 2005) has contributed to significant advances in many domains. It is time for the Science of Love to embrace complexity and to call for new models and for new inter and transdisciplinary research approaches.

In this paper, we lay out a set of assumptions as cornerstones for the development of an Integrative Theory of the Complexity of Love (C.ofLove) as the 
foundation for an Integrated Science of Love. Informed by a complex systems perspective, these assumptions address the questions of: what is love, how is love organised, where is love, when is love, how is love realised and why does love matter? In order to fully address these questions, we need to develop novel inter and transdisciplinary research methods and approaches.

\section{Towards an Integrative Theory of the Complexity of Love: Contributions from a complex systems perspective}

We propose that love shares many properties with complex systems, and that it is best understood from a complex systems perspective (Byrne \& Callaghan, 2013; Érdi, 2007; [blinded for review], in preparation; [blinded for review], 2015; Nicolis \& RouvasNicolis, 2007; Kelso, 1995): Love is self-organised, it cannot be created or imposed from the outside (there is no external controller); it is other and more than the sum of its parts (individual contributions, properties of their interaction) and exhibits capacities or properties that are not reducible to the individuals or the level of components; it cannot be localised but it can be recognised by its effects; it emerges from the recurrent interaction between individuals and the relation between the individuals and the whole system of which they are a part; upon its emergence, it constrains the individuals and their coordination through 'top-down' effects; it is dynamic, adaptive and contextdependent.

In the following, we will use complexity concepts to the extent that they assist our explanation, we will not, however, review complexity theories and suggest that the unfamiliar reader consult texts introducing some basic concepts (Byrne \& Callaghan, 2013; Capra, 2007 Érdi, 2007; Haken, 2008; Kelso, 1995; [blinded for review], 2015; Nicolis \& Rouvas-Nicolis, 2007; Sporns, 2007; Thelen, 2002). 
In this paper, we present basic assumptions for an Integrative Theory of the Complexity of Love (C.ofLove). For this, we draw on a recently developed theoretical framework that conceptualises Families as Complex Systems (FACS) ([blinded for review], in preparation a). FACS was constructed through a complex-systems informed (Byrne \& Callaghan, 2013; Thornerg, 2012), grounded-theory approach (Bryant \& Charmaz, 2007), followed by iterative cycles of exploration of empirical data and literature reviews and was developed in the context of the investigation of change and resilience processes in multi-challenged families with at-risk children. Love was identified as an emergent relational force, characterised by powerful top-down effects over the individuals, their dyadic relationships and the families, as whole systems of relationships ([blinded for review], in preparation a). Love appeared as a central resilience-building process, activating and driving positive family and parental changes ([blinded for review]; [blinded for review], in preparation b). This work was further extended to integrate different views on love and to develop a complex systems perspective on love

\section{Interpersonal coupling and the emergence of relational potentials/capacities}

The key focus for FACS in understanding family relationships, is the process of coupling, drawing on field of coordination dynamics (Kelso \& Engstrom, 2006). In FACS, coupling is considered both as a process: the dynamic manner by which individuals become interdependent, and as an outcome: representing the strength of the relationships, manifest in the way one individual behaves, to some degree, as a function of the other. Coupling can be either be transient or patterns of coupling may emerge that correspond to bonds. Coupling occurs in many domains (emotional, cognitive, behavioural, neurophysiological) and at many levels of organisation of relationships (individual; between individuals; between bonds; between networks of bond), and may 
be defined by a certain number of dimensions. In terms of its qualities, every coupling practice can be characterised by a set of properties that exist in a spectrum ranging from fully negative to positive expressions of a bipolar complementary pair (related by the binary operator “〜”) (Kelso \& Engstrom, 2006). Even though subject to revision, FACS identified an initial list of 48 individual coupling properties (e.g. misattention attention; negativity $\sim$ positivity; selfishness $\sim$ altruism; positive $\sim$ negative appreciation of the other; opposition to $\sim$ support of other) and 32 reciprocal coupling properties (e.g. desynchronisation $\sim$ synchronisation; competitiveness $\sim$ cooperation; amplification of the negative $\sim$ amplification of the positive). Many of these properties have been studied by the sciences of interpersonal relationships and of love, but here they are conceptualised as non-linearly interacting particles in a network of properties that characterise coupling practices. We hypothesise that some of these properties have critical positions in the network and influence others by amplifying or damping them, within and between levels. FACS proposes that there are relational forces that emerge from the interaction between the individual and reciprocal properties, within each level, and between levels. These forces are associated with the activation of emergent potentials of the couplings/bonds, of which FACS identifies 16, also understood as complementary pairs ([blinded for review], in preparation). These potentials might be taken as coordination variables, or order parameters. Once they emerge they constrain, through 'top-down' effects the lower-levels. They also exhibit variation and fluctuation but changing at a slower pace than those lower-levels.

The emergent potentials may remain dormant or be active to different degrees. When activated, they become true capacities of the coupling/bonds, conferring the individuals, and their coordination, with abilities that cannot be reduced to any single property at those levels. These potentials are best identified indirectly through their 
influence and effects on the individuals. They can be activated by some specific properties acting as triggers (e.g. those that occupy critical positions in the coupled network of properties) and other internal (e.g. changes in the network of bonds) and external factors (e.g. life challenges). These potentials may be positive or negative. Their activation sustains love as a field of influence that shapes, in positive or negative ways, the individuals' contributions to the relationships (patterns of individual coupling) and their coordination (reciprocal coupling). Love, and the potentials that sustain it, are responsive to perturbations, show dynamic variation and stability, critical fluctuations, critical slowing down and phase transitions, as observed in other complex dynamical systems (Kelso, 1995). They may be amplified or dampened by specific internal and external conditions surrounding the coupling or dissipate, until re-activated.

Different configurations of properties, at lower-levels, may be associated with different configurations of emergent potentials. These configurations, and the couplings between the multiple levels, will change over time. There may be equifinality (different initial conditions leading to similar end states) and multifinality (similar initial conditions leading to different outcomes) (Bertalanffy, 1968). Bonds can be characterised by dynamic patterns of emergent potentials on a changing landscape of attractors (Kelso, 1995). The emergent field may be sustained beyond the moment of its activation. Therefore, the individuals may remain under its effects for more or less extended periods of time. The potentials exhibit hysteresis, where the state of a system is dependent on its history (Kelso, 1995): the more they are activated, the more easily they will be activated in the future; the more frequently they are activated, the more likely for its effects to sum up and be resilient to perturbation and for a bond to have strong resilient pattern. The activation of the potentials is likely dependent on particular configurations of properties of coupling at lower levels and their strength. It is also 
likely that there are activating effects within the emergent level, for example, with the activation of an emergent potential A leading to the subsequent activation of an emergent potential B.

Figure 1 illustrates the organization of the relationships into multiple levels, up to the level of the dyad or bond and its emergent potentials.

-Insert Figure 1 around here-

In the bottom part of the figure the arrows represent the totality of the coupling contributions, as whole packets of influence travelling from individual 1 to individual 2 and vice versa. These contributions result from the interaction of different properties, that are organised in a network, with some having critical positions in influencing others. In the middle of the figure, the coordination between the individuals and their contributions is characterised by reciprocal coupling properties, which are also organised in a network. The interaction between the individual contributions and their reciprocal coupling will lead to the emergence of relational potentials that, when activated, generate a field of influence that constrains and shapes the individuals and their reciprocal coupling processes, in a circular recursive process. The left side of the figure illustrates the structure of these coupled networks of properties within and between levels, acknowledging that the conditions for their activation and the character of their dynamics are still largely unknown.

In a network of bonds, as in systems such as families, the bonds will interact through their emergent potentials in constructive or destructive ways, leading to the formation of overall fields that modulate (amplifying or damping) each other's properties. The same process will apply to the interaction between microsystems (e.g. families), constituted as networks of bonds, where the internal bonds will be constrained or facilitated by the quality, structure and resonance dynamics (the way some bonds 
may drive others amplifying their effects) associated with the configuration of the coupling (e.g. system-to-system; bond-to-system) between internal and external bonds.

These essential ideas about the processes of interpersonal coupling are fundamental for understanding the complexity of love.

\section{Core assumptions for an Integrative Theory of the Complexity of Love}

In this section we elaborate on the previous insights related to the multi-level relational organisation of love to present the core founding assumptions of an Integrative Theory of the Complexity of Love (C.ofLove).

\section{What is love? Love as an emergent relational force}

Due to the complexity of love, different facets will be more salient depending on the perspective one adopts. From a complex systems perspective, love is defined as an emergent relational force, sustained by flexible and resilient patterns of (mostly) positive potentials that emerge from coupling processes. Table 1 presents a brief description of the positive pole of the emergent potentials of coupling/bonds that have been identified by FACS and that we propose are associated with love as an emergent relational force ([blinded for review], in preparation a).

-Insert table 1 around here-

These potentials can be identified through their effects on the individuals, that are potentially powerful and transformative. The emergent potentials are likely to have particular positive cognitive and emotional correlates and neurophysiological signatures that can be investigated in relation to the underlying configurations of properties of individual and reciprocal coupling, from which they emerge. As a consequence of the experience of the effects of love, the positivity of the individual coupling and their coordination are increased, suggesting a positive feedback loop. 
Each love experience is unique, not only due to its determinants in terms of the configurations of properties of coupling involved (e.g. responsibility would be a salient individual property of coupling underlying "parental love"), but also due to the different types of effects (e.g. empowering, reparative) associated with the activation of specific positive potentials.

Love can be associated with (i) the experience of transient effects of the activation of positive emergent potentials of coupling (which makes it possible to have a momentary/passing experience of love with a stranger) or (ii) the experience of the extended effects of emergent potentials activated in bonds (stable patterns of coupling) ([blinded for review], in preparation a). As an emergent force, love is best conceptualised as a transient experience, however it may also be sustained as well as repeatedly re-activated. The love field may be sustained as a result of the strength of the emergent potentials, that result from the effects of single strong activation events, or as a result of repeated (re)activation that serves to reinforce the potentials. The sustenance of the love field, and the effects on the individuals under its influence, is central to the maintenance, enhancement and developmental complexity of love.

It is critical to understand which configurations of properties at lower levels (individual and reciprocal coupling) are associated with the activation of which emergent potentials. It is also relevant to understand how factors such as culture, or the history of the relationship, shape the importance of those properties and the experience of the emergent potentials of love.

Every love experience is unique, although based in common processes. The domains of life where coupling is practiced and the specific properties of coupling involved, may contribute to variations ("twists" or "feel") in the experience of the effects of the emergent relational potentials and, eventually, to different "types" of love. 


\section{How is love organised? The self-organisation (and ecology) of love}

Love is a self-organised phenomenon (Morin, 2005). There is no external controller and it is not possible for an external agent to force or control the creation or course of love: love feeds on itself in a recursive way. Nevertheless, knowledge of love's key processes could inform interventions aimed at "guiding" its self-organisation (Prokopenko, 2014). While love is internally organised there are many factors, both internal and external, that shape it. Love is sustained and constrained by a rich ecology of multi-level processes, of different types.

Figure 2 illustrates the different levels of the organisation of the ecology of love, drawing on Bronfenbrenner's (2003) ecological model of human development.

-Insert Figure 2 around here-

Figure 2 integrates the varieties of coupling processes that connect the different levels of the ecological organisation of love. More integrative research is required to explore these processes, their mutual couplings and all the dimensions implicated therein. The emergence and activation of love is influenced by characteristics of other dimensions of the functioning of the individual (e.g. biology; capacities), of the bonds and the microsystemic environments such as families (e.g. values, identity, intentions, goals and dreams, rules, rituals, functional capacities, etc.), as well as the contents of the couplings (domains of life where coupling is practiced). It might also vary due to the history and nature of their interaction with other social systems, environmental conditions (e.g. the material, natural, cultural or technological) and life events (e.g. births, deaths, illnesses, unemployment).

\section{Where is love? Love as a distributed property and a multi-level phenomena}

Love cannot be localised in a single point. It is a distributed property of relational systems. It exists between and beyond the individuals, and is sustained 
through their coupling. Nevertheless, the spatial dimension of love can be investigated in terms of the extension of its effects in relation to the different organisation of the relationships involved. Depending on the relative position where one would place an observer in the ecology of love (the star in Figure 2), different perspectives will emerge (Goguen \& Varela, 1979).

At the individual level, we can talk of a potential and capacity for love. At the level of their coordination one can speak of loving interactions. Nevertheless, the emergence of love is located in neither of these levels alone since, while dependent on them, love transcends them. The relationship between levels is particularly important in the emergence of love and should be a key target of future research. Love emerges from the bottom-up, but there might be different relative contributions of each level, in different bonds, with their adaptation and developmental values varying for different contexts.

Once activated, love can be sustained, amplified, dampened, supported or constrained by different dimensions in a given ecology. For the individuals involved, the impact of the activation of love will differ depending on their initial capacity for love. This activation, characterised by the emergent potentials or capacities, we can identify experiences of love and love bonds. In (multi-dyadic) microsystems (e.g. families), the bonds will interact through resonance processes and couple in constructive or destructive ways, amplifying or damping the emergent love field. When the interactions sustain or amplify a love field, we can identify loving environments. At the mesosystem level, coupling between microsystems (e.g. families) will also be characterised by direct loving vs. non-loving interactions, as well as indirect contributions through the creation of favourable conditions for the internal coupling within a given system, giving rise to (more or less) love-supporting communities. At the 
macrosystem level, the wider social, cultural and economic structures and processes characterising societies (e.g. discourses, values, role distribution, social functions, macro-organisational practices) will impact on the nature of the couplings at lowerlevels (e.g. gender roles will impact on the family time and how much certain coupling properties, such as attention or cooperation will be practiced), giving rise to lovesupporting societies which generate processes facilitating positive couplings, at different levels, thereby amplifying love. Finally, the coupling with the natural, material and technological environments will also create favourable or unfavourable conditions through more or less love-supporting environments (e.g. the housing conditions or a given use of technology will impact the quality of reciprocal coupling).

\section{When is love? Love as a dynamical system}

Love is dynamic and adaptive, and its emergence may be dependent on particular conditions. Developmental and historical events are very important when exploring love together with the recognition of the coupling of different timescales across levels of the ecology of love (Figure 2).

The activation of love potentials may operate under a process similar to neural integration or summation (Llinas, 2008). The activation of neuronal action potentials is dependent on the spatial (simultaneous) and temporal (sequential) summation of excitatory and inhibitory inputs that reach a particular threshold. Likewise, the activation of the love's potentials may be dependent on the properties of lower-level configurations combining (likely in a non-linear manner) to reach a particular threshold. The fact that different configurations of properties may lead to an experience of love may be an adaptive feature of love, increasing its robustness (Waddington, 1942). It is also likely that fluctuations in lower-level properties (e.g. variations in the daily individual contributions or reciprocal coupling) can be accommodated, to a certain 
extent, without significant changes in the emergent patterns of potentials. Their effects may persist, for a duration, in the absence of reactivation. The activation of love may be limited to brief transient experiences that may not be strong or frequent enough for transformation into a love bond. This is also why 'unloving persons' and 'unloving interactions' will occasionally participate in love experiences without love being the dominant pattern of experience. Love is sustained as a predominantly positive flexible and resilient pattern of emergent potentials.

From a dynamical perspective, we can view love as an attractor state: thus, the degree to which system can recover from fluctuations or perturbations and, return back to normal (or even enhanced levels of love) may be seen as a measure of its robustness (or "strength"). Under certain conditions, however, fluctuations or perturbations may reach critical levels and lead to qualitative changes to other attractor states (e.g. from love to non-love or between different types or experiences of love). Such transitions need to be investigated in terms of the parameters driving them.

Love is likely to show unique developmental dynamics for a given system, but also regularities across different systems. There are developmental questions to be addressed regarding, for example, the relations between different potentials e.g some may be more easily activated, precede or facilitate others. Some potentials may be less commonly reported than others, perhaps only experienced in developmentally more complex forms of love. A love experience may also implicate cascades of activation events, with the activation of some potentials acting as triggers or amplifiers for others, in a manner analogous to signalling cascades in biological systems. These processes require exploration.

\section{How is love realised? The effects of love}


Love is realised through the experience of positive emergent potentials and is best identified through its effects. These effects are likely to involve emotional, cognitive, motivational and behavioural systems and to present particular neurophysiological correlates. Future research needs to develop integrated assessment protocols that combine subjective (e.g. self-reported) and objective (e.g. behavioural expressions) assessments of the activation of love with the concurrent investigation of neurophysiological processes, considering them in the context of the underlying patterns of coupling.

\section{Why love matters? The powerful and transformative effects of love}

Through its effects, love can surpass other human strengths, while enhancing and mobilising them. It supports change and adaptation, enhancing capacities both at the level of the individuals and the bonds or systems of close bonds. The experience of love appears to have a further constructive effect on the individual's capacity for love and the dynamics of loving interactions. The processes associated with the activation of love and its corresponding effects require deeper exploration, as they may underlie the reports of enhanced well-being, happiness, and capacity of individuals under the influence of love ([blinded for review], in preparation a). This is important as it may be possible to intentionally promote the activation of love and to mobilise its positive effects love ([blinded for review], in preparation a). Love then becomes a critical resource in the face of adversity or to facilitate positive change and adaptation in individuals and systems such as families ([blinded for review], in preparation a). A thorough identification of processes by which love can be activated and intentionally enhanced or mobilised may have significant implications for the full translational development of an Integrated Science of Love towards building happier, healthier, more positive and loving futures. 


\section{Conclusion}

To use love as a label to refer to broad categories of relationships, is to reduce its complexity as a special property of human relationships, with potentially powerful and transformative effects in shaping human flourishment. In this way, love readily becomes objectified, and notions of its internal organisation are lost. Alternatively, one can describe love as a practice or an art (Fromm, 1957). The more frequent and positive the practice(s) of love at the level of the individuals and their coordination, the more likely the activation of love, and the higher the strength of its effects and its resilience.

The true nature of love lies in its processual nature. As a process, it emerges out of the interpersonal resonance between individuals pulsating and responding to each other, moment by moment, in an embodied dance of life that transcends materiality and substance. The practices of coupling can be seen as wholes, as quanta carrying relational information and travelling in circles, from one person to the other while mutually constituting them. Love is a constructive process in the relational matrix that constitutes reality (Whitehead, 1978). It is in the flux of love experiences that the best of humanity is carved and showcased.

Other practices and processes co-occur or compete with it. Some constellations of properties of coupling, leading to certain potentials, can be seen as sub-sets (e.g. attachment), sub-processes and facilitators of a full and richer love experience. In a sense, as long as there is minimal experience of one of love's emergent potentials there is a 'minimum' of love, which can grow, expand, differentiate and integrate towards increasing levels of complexity, as a living organism. Love encompasses and integrates the many practices of human relating, and its multiple expressions. It is sustained in positive practices but it is not only defined in relation to the negative as it might even integrate it, but surpass it, as part of its fluctuant flow. Love integrates Many 
components of human existence into a unifying One, adding them by One, for, being complex, it is more and other than their sum (Morin, 2005; Whitehead, 1978).

Based on a complex systems perspective of family relationships, and the recent development of a Framework of Families as Complex Systems, we have proposed a set of assumptions as cornerstones for the development of an Integrative Theory of the Complexity of Love (C.ofLove) as a preliminary foundation for an Integrative Science of Love. This new framework calls for a complex-systems informed research approach, while supporting the mapping and integration of existing contributions. It will likely challenge a wide community of researchers, across disciplines, to develop and adapt tools and methods suitable for the scientific investigation of the complexity of love. We hope these contributions stimulate new disciplinary and interdisciplinary dialogues as well as the translational potential of an Integrated Science of Love. 


\section{References}

Aron, A., Fisher, H. E., \& Strong, G. (2006). Romantic love. In A. L. Vangelisti \& D. Perlman (Eds.). The Cambridge handbook of personal relationships (pp. 595614). New York: Cambridge University Press.

Aron, A., Fisher, H., \& Strong, G. (2006). Love. In D. Perlman \& A. Vangelisti (Eds.), Cambridge handbook of personal relationships (pp. 595-614). New York: Cambridge University Press.

Beauregard, M., Courtemanche, J., Paquette, V. \& Landry St-Pierre, E. (2009). The Neural Basis of Unconditional Love. Psychiatry Research, 172 (2), 93-98.

Berscheid, E. (2010). Love in the fourth dimension. Annual review of psychology, 61,125.

Bertalanffy, L. V. (1968). General Systems Theory. Foundations, development, applications (revised edition). New York: George Braziller.

Bronfenbrenner, U. (2005). Making human beings human: Bioecological perspectives on Human Development. Thousand Oaks: Sage.

Bryant, A. \& Charmaz, K. (2007). The SAGE Handbook of Grounded Theory. Thousand Oaks: Sage Publications

Byrne, D., \& Callaghan, G. (2013). Complexity Theory and the Social Sciences: The State of the Art. Routledge.

Byrne, D., \& Ragin, C. C. (2009). The Sage handbook of case-based methods. Thousand Oaks: Sage Publications.

Cacioppo, S., Bianchi-Demicheli, F., Hatfield, E. Rapson, R. L. (2012). Social neuroscience of love. Clinical Neuropsychiatry, 9(1), 3-13.

Cacioppo, S., Bianchi-Demicheli, F., Hatfield, E., \& Rapson, R. L. (2012). Social neuroscience of love. Clinical Neuropsychiatry, 9(1), 3-13. 
Capra, F. (2007). Complexity and life. Systems Research: The Official Journal of the International Federation for Systems Research, 24(5), 475-479.

Capra, F., \& Luisi, P. L. (2014). The Systems View of Life: A Unifying Vision. Cambridge University Press.

Dias, A. C., Machado, C., Gonçalves, R. A. \& Manita, C. (2014). Discursos socioculturais sobre o amor em portugal: um percurso geracional? [Sociocultural discourses in love in Portugal: a generational pathway?] Psicologia 28 (1): 1-18.

Diener, E., \& Seligman, M. E. P. (2002). Very happy people. Psychological Science, $13(1), 81-84$.

Fehr, B. (1994). Prototype-based assessment of laypeople's views of love. Personal Relationships, 1(4), 309-331.

Fehr, B. \& Russell, J A (1991). The Concept of Love Viewed From a Prototype Perspective. (1991). Journal of Personality and Social Psychology, 60(3)(425438).

Fehr, B., Sprecher, S., \& Underwood, L. G. (2008). The science of compassionate love: Theory, research and applications. Wiley-Blackwell.

Fehr, B., Sprecher, S., \& Underwood, L. G. (2009). The science of compassionate love: Theory, research and applications. Wiley-Blackwell.

Fredrickson, B. L. (2000). Cultivating positive emotions to optimize health and wellbeing. Prevention \& Treatment, 31(1).

Fredrickson, B. L. (2013). Love 2.0: Finding Happiness and Health in Moments of Connection. New York: Hudsen Stress Press.

Fromm, E. (1957). The art of loving. London: Unwin books.

Goguen, J. A., \& Varela, F. (1979). Systems and distinctions: Duality and complementarity. International Journal of General Systems, 5, 41-43. 
Goldstein, E. B. (2010). Encyclopedia of perception. Thousand Oaks: SAGE Publications.

Goldstein, J. (1999). Emergence as a Construct: History and Issues. Emergence, 1(1), $49-72$.

Gonzaga, G. C., Keltner, D. Londhal, E. A., \& Smith, M. D. (2001). Love and the commitment problem in romantic relations and friendships. Journal of Personality and Social Psychology, 81, 247-262.

Graham, J. M. (2010). Measuring Love in Romantic Relationships: A Meta-Analysis. Journal of Social and Personal Relationships, 28(6): 748-71.

Haken, H. (2008), Scholarpedia, 3(8):1401. doi:10.4249/scholarpedia.1401

Harlow, H. F. (1958). The nature of love. American Psychologist, 13, 673-685

Hojjat, M. \& Cramer, D. (2013). Positive psychology of love. New York. Oxford University Press.

Kelso, S. (1995). Dynamic patterns: self-organisation of brain and behaviour. USA: MIT Press.

Llinas, R. (2008), Scholarpedia, 3(8):1490. doi:10.4249/scholarpedia.1490

[blinded for review] (in preparation a) [book contracted]

[blinded for review] (in preparation b)

[blinded for review] (2015)

[blinded for review] (2014)

Morin. E. (2005). Introduction à la pensée complexe. Paris: Éditions du Seuil. [Originally published in 1990].

Nicolis, G. \& Rouvas-Nicolis, K. (2007). Complex systems. Scholarpedia, 2(11):1473. doi:10.4249/scholarpedia. 1473 
Noller, P. (1996). What is this thing called love? Defining the love that support marriage and family. Personal Relationships,3, 97-115.

Passos, P., Davids, K., \& Chow, J. Y. (2016). Interpersonal Coordination and Performance in Social Systems. Oxon: Routledge.

Prokopenko, M. (Ed.) (2014). Guided self-organisation: Inception. Berlin: SpringerVerlag.

Regan, P. (2008). General theories of love. In P. Regan (Ed.). The mating game: A primer on love, sex and marriage (pp. 61-79). Los Angeles: Sage Publications.

Reis, H. T. \& Aron, A. (2008). Love. What is it, why does it matter, and how does it operate? Perspectives on psychological science, 3, 1, 80-86. doi: 10.1111/j.17456916.2008.00065.x

Reis, H. T., Collins, W. A., \& Berscheid, E. (2000). The relationship context of human behavior and development. Psychological Bulletin, 126(6), 844-872.

Romesín, H.M. \& Verden-Zöller, G. (2012). The Origin of Humanness in the Biology of Love. Andrews UK Limited.

Saphire-Bernstein, S. \& Taylor, S. E. (2013). Close relationships and happiness. In I. Boniwell, David, S. A., \& Ayers, A. C. (Eds.), The Oxford Handbook of Happiness (pp. 821-833). New York: Oxford University Press.

Shaver, P. \& Mikulincer, M. (2006). A behavioural systems approach to romantic love relationships: Attachment, caregiving and sex. In Sternberg, R. J. \& Weis, K. (Eds). The new psychology of love (pp.35-64). New Haven: Yale University Press.

Shaver, P. R. \& Hazan, C. (1988). A biased overview of the study of love. Journal of Social and Personal Relationships, 5(4), 473-501.

Shaver, P. R. \& Hazan, C. (1988). A biased overview of the study of love. Journal of Social and Personal Relationships, 5(4), 473-501. 
Simpson, J. A. \& Campbell, L. (Eds.) 2013. The Oxford Handbook of Close Relationships. Oxford: Oxford University Press.

Sporns, O (2007), Scholarpedia, 2(10):1623. doi:10.4249/scholarpedia.1401

Sternberg, R. J. (1986). A Triangular Theory of Love. Psychological Review, 93(2), 119_ 135.

Sternberg, R. J. \&Weiss, K. (2008). The new psychology of love. New York. Yale University.

Thornberg, R. (2012). Informed Grounded Theory. Scandinavian Journal of Educational Research, 56(3), 243-259.

Tomkins, S. (1984). Affect theory. Approaches to Emotions, 163, 163-165.

Toomela, A. (2014). Mainstream Psychology. In T. Teo (Ed.), Encyclopedia of Critical Psychology (pp. 1117-1125). New York: Springer.

Underwood, L. G. (2009). Compassionate love: A framework for research. In B. Fehr, S. Sprecher, \& L. G. Underwood (Eds.), The Science of Compassionate Love: Theory, Research, and Applications (pp. 3-26). West Sussex: John Wiley \& Sons.

Vaughan, J., Eisenberg, N., French, D. C., Puwono, U., Suryanti, T. A., \& Pidada, S. (2009). Compassionate love: Concluding reflections. In B., Fehr, S., Sprecher, \& L. G., Underwood (Eds), The science of compassionate love. Theory, research and applications (pp. 433-452). Chichester, West Sussex: Wiley-Blackwell.

Waddington, C. H. (1942). Canalization of development and the inheritance of acquired characters. Nature, 150 (3811): 563-565.

Whitehead, A. N. (1978). Process and reality (corrected edition). New York: The Free Press.

Zeki, S. (2007). The Neurobiology of Love. FEBS Letters, 581(14), 2575-79. 
Table 1. Short definition of love's positive emergent potentials of coupling/bonds

\section{LOVE'S EMERGENT POTENTIALS}

High Elasticity: The extent to which the coupling/bond, in response to events and internal and external demands, is capable of contracting (increasing frequency of intensity of coupling), increase its positive properties and leading the individuals to experience a sense of union and increased shared strength and the extent to which it is capable of expanding (decreasing frequency or intensity of coupling) while preserving its positive properties and overall strength.

Positive Resonance: The extent to which the coupling/bond is responsive to external influences in a way that amplifies or preserves its positive patterns.

Positive Magnetism: The extent to which the coupling/bond exerts an attractive force between the individuals, namely, leading them to purse closeness and intimacy.

High Integration: The extent to which the coupling/bond is a coherent and integrated whole, creating a sense of connectedness and belonging and leading the individuals to feel a part of the other or of something bigger.

High Propelling Energetic potential: The extent to which the coupling/bond transfers propelling and mobilising energy to the individuals resulting in a feeling of strength that "comes from within", confidence, energy goal orientation and motivation for action.

High Vitalising potential: The extent to which the coupling/bond transfers vitalising energy to the individual who, under its influence experience a general feeling of well-being and vitality ("feeling alive", "feeling well or awake to the world"), strength and health.

High Expansive potential: The extent to which the coupling/bond enhances and expands the individuals emotional, cognitive and behavioural capacities leading them to feel they are capable of "doing more", experiencing a "bigger world" or achieving things they would otherwise not be as able to do.

Positive Aesthetics: The extent to which the coupling/ bond enhances the feeling of aesthetics and the sensitivity of the individuals to recognise and appreciate the "good and the beautiful".

Positive Protection and Healing: The extent to which the coupling/bond offers the individuals a feeling of protection and sheltering from the external world, as well as context for healing and reparation, associated with sensations and feeling of "warm" and warmth, and of being shielded by the coupling/bond.

Positive Meaningfulness: The extent to which the coupling/bond presents confers to individuals a feeling of meaningfulness and purpose in life and making them feel special.

Collective development: The extent to which the coupling/bond evolves and promotes its own development becoming richer and more flexible with time, introducing novelty and variations so the individuals feel that the bond "grows" and "strengthens" or the extent to which the bond seems to tend to degeneration, stagnation or rigidity, leaving the individual to feel the bond is "weakening" or becoming "poor".

High Happiness: The extent to which the coupling/bond confers the individual a feeling of full plenitude, fulfilment and happiness, when in its context or under its influence, independent of other sources of difficulties of constrains in the individual's life.

Positive Vulnerability: The extent to which the coupling/bond allows the individual to experience a positive sense of vulnerability associated with a full openness to the relational experience and to the "good and the bad" in it, namely the willingness to risk pain or suffering for the sake of the good that may derive from the coupling/bond to the self or the other.

Positive Response to Threat: The extent to which the coupling/bond prompts the individually to respond to threats to preservation of the coupling/bond in a positive way by engaging in actions that may lead to positive outcomes.

Positive Nurturing/Scaffolding: The extent to which the coupling/bond supports and scaffolds the individuals' development so they feel that, in the context of the bond, their growth and development is accelerated or supported.

Sensitivity to contextual conditions: The extent to which the coupling/bond responds to contextual conditions in positive ways influencing the individuals to act as to manage or dealt in those conditions in order to enhance or preserve the bond. 
Figure 1. Multi-level organisation of relationships: from the individual contributions to the emergent potentials of the bonds

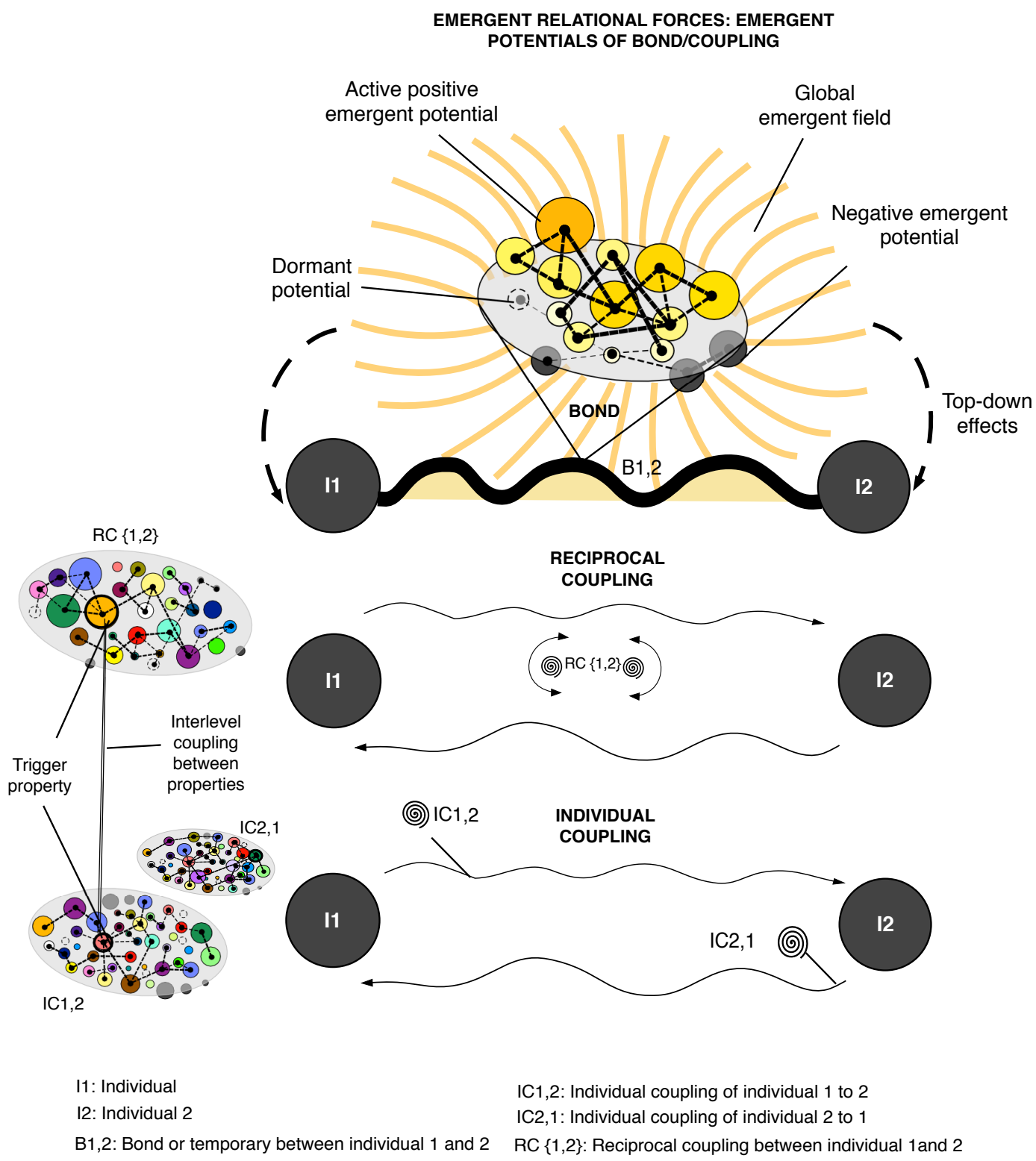


Figure 2. The ecology of love

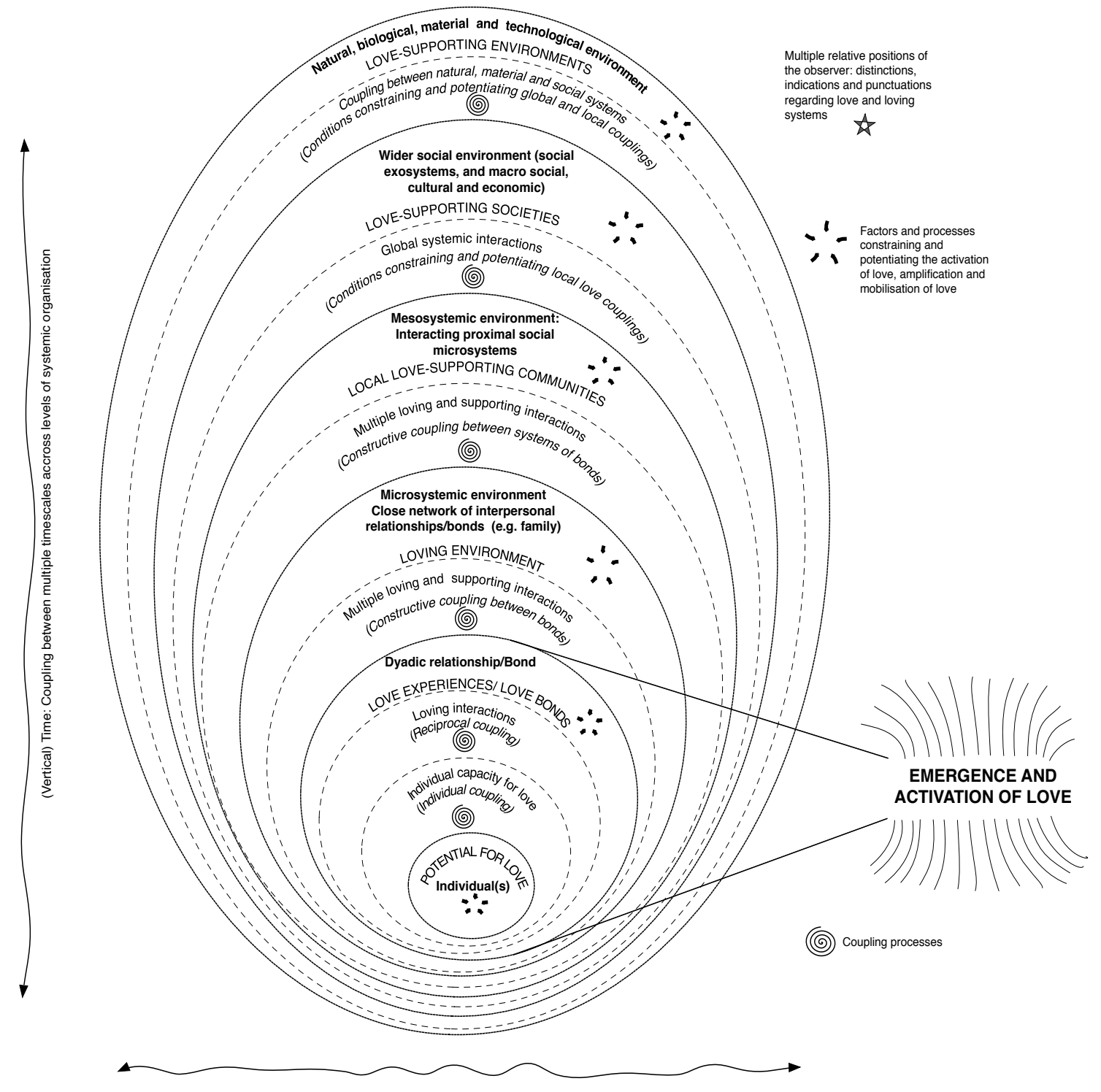

(Horizontal) Time: History of changes in content and processes of each system, at different levels 